\title{
Functional interactions among members of the meiotic initiation complex in fission yeast
}

\author{
Silvia Steiner · Jürg Kohli $\cdot$ Katja Ludin
}

Received: 15 September 2009/Revised: 11 March 2010/Accepted: 11 March 2010/Published online: 3 April 2010

(c) Springer-Verlag 2010

\begin{abstract}
DNA double-strand breaks (DSBs) initiate meiotic recombination in Schizosaccharomyces pombe and in other organisms. The Rec12 protein catalyzes the formation of these DSBs in concert with a multitude of accessory proteins the role of which in this process remains to be discovered. In an all-to-all yeast two-hybrid matrix analysis, we discovered new interactions among putative members of the meiotic recombination initiation complex. We found that Rec7, an axial-element associated protein with homologies to Saccharomyces cerevisiae Rec114, is interacting with Rec24. Rec7 and Rec24 also co-immunoprecipitate in $S$. pombe during meiosis. An amino acid change in a conserved, C-terminal phenylalanine in Rec7, F325A interrupts the interaction with Rec24. Moreover, rec7F325A shows a recombination deficiency comparable to $r e c 7 \Delta$. Another interaction was detected between Rec12 and Rec14, the orthologs of which in S. cerevisiae Spo11 and Ski8 interact accordingly. Amino acid changes Rec12Q308A and Rec12R309A disrupt the interaction with Rec14, like the according amino acid changes Spo11Q376A and Spo11RE377AA loose the interaction with Ski8. Both amino acid changes in Rec12 reveal a recombination deficient rec $^{-} 2^{-}$phenotype. We propose
\end{abstract}

Communicated by M. Yamamoto.

Electronic supplementary material The online version of this article (doi:10.1007/s00294-010-0296-0) contains supplementary material, which is available to authorized users.

S. Steiner · J. Kohli $\cdot$ K. Ludin $(\bowtie)$

Institute of Cell Biology, University of Bern,

3012 Bern, Switzerland

e-mail: katja.ludin@izb.unibe.ch that both Rec7-Rec24 and Rec12-Rec14 form subcomplexes of the meiotic recombination initiation complex.

Keywords Meiosis - Recombination - Spo11 complex · Schizosaccharomyces pombe

\section{Introduction}

Meiosis is essential for all sexually reproducing eukaryotes to form haploid gametes or spores from diploid cells. One round of chromosome duplication is followed by two rounds of chromosome segregation. In the first meiotic division (meiosis I) homologous chromosomes separate, whereas in the second meiotic division (meiosis II) sister chromatids move apart. Faithful chromosome segregation is crucial for the production of viable gametes and is enabled by physical connections between the two homologs (chiasmata) caused by recombination events. In addition, meiotic recombination contributes profoundly to genetic diversity. After obligatory DNA replication, recombination is initiated by the formation of DNA double-strand breaks (DSBs) catalyzed by the Spo11 protein (reviewed in Keeney 2001). Spo11 shares homology with subunit A of archaeal topoisomerase Top6 (Bergerat et al. 1997). It is ubiquitously found in organisms of the Eukarya and Archaea kingdom, however its function was mainly studied in the ascomycete Saccharomyces cerevisiae. The DNA DSB is formed by two trans-esterification reactions involving active site tyrosines of a Spo11 dimer. Spo11 remains transient covalently attached to the 5'-end of the broken DNA (Keeney et al. 1997). Later, Spo11 gets released from the DNA by endonucleolytic cleavage (Neale et al. 2005). The liberated 5'-ends allow further strand resection, probably by exonucleolytic activities. Exposed 
single-stranded DNA strands are substrates to recombinases (e.g. Rad51 and Dmc1, among others), the strand invasion ability of which eventually leads to the formation of crossovers or non-crossovers.

Next to Spo11, nine proteins are known to be indispensable for DSB formation and thus meiotic recombination in S. cerevisiae: Mre11, Rad50, Xrs2, Ski8, Rec102, Rec104, Mer2, Mei4, and Rec114 (reviewed in Keeney 2001). Based on physical and genetical interactions among these 10 proteins, three subgroups have been defined: Mre11, Rad50, and Xrs2 (MRX complex); Spo11, Ski8, Rec102, and Rec104; and Rec114, Mer2, and Mei4 (Arora et al. 2004).

The evolutionary conserved MRX complex is not only required for meiotic DSB formation, but also holds numerous functions in meiotic and mitotic DNA repair (reviewed in Borde 2007). However, its dependency on DSB formation is not conserved in Arabidopsis thaliana (Puizina et al. 2004) or in fission yeast (Young et al. 2004).

Rec102 and Rec104 seem to form a functional unit; they interact genetically (Salem et al. 1999; Kee and Keeney 2002; Jiao et al. 2003) and physically (Arora et al. 2004; Kee et al. 2004; Maleki et al. 2007; Kee and Keeney 2002; Jiao et al. 2003). Both localize to chromatin at the time of DSB formation. Rec102 is distributed uniformly across the chromosomal DNA during meiosis, with preference for chromatin loops, but not for hotspot regions (Kee et al. 2004). Nuclear localization and chromatin association of Rec102 and Rec104 is inter-dependent and depends on Spo11 and Ski8 as well (Kee et al. 2004). In addition, Spo11 association with chromatin requires Rec102/Rec104 (Prieler et al. 2005; Sasanuma et al. 2007).

Ski8 and Spo11 interact physically (Uetz et al. 2000; Arora et al. 2004). Ski8 re-localizes during meiotic prophase from the cytoplasm to the nucleus in a Spo11 dependent manner (Arora et al. 2004). Spo11 and Ski8 need to interact for DSBs to be formed and it is presumed that Ski8 stabilizes the association of Spo11 with meiotic chromosomes (Arora et al. 2004). Furthermore, Ski8 contains the classical seven-bladed propeller structure of WD repeat proteins (Matsumoto et al. 1993; Madrona and Wilson 2004), which is a widely employed protein interaction motif, serving as a scaffold for the assembly of other proteins (reviewed in Smith et al. 1999), e.g. it promotes the interaction between Spo11 and Rec102/Rec104 (Arora et al. 2004). The function of Ski8 as a loading platform might also explain its other function in RNA metabolism in vegetatively growing cells (Ridley et al. 1984). This role, however, is genetically separable from its role in meiosis (Arora et al. 2004).

The third subgroup consists of Mer2, Mei4, and Rec114. The three proteins co-localize on meiotic chromosomes and co-immunoprecipitate (Maleki et al. 2007; Li et al.
2006). Mer2 interacts with itself, Rec114, Mei4, and Xrs2 (Arora et al. 2004). Mer2 forms foci on meiotic chromosomes and gets phosphorylated by $\mathrm{Cdc} 28-\mathrm{Clb} 5 / \mathrm{Clb} 6$ and Cdc7-Clb4, which is essential for its interaction with other DSB proteins and their loading to chromatin (Henderson et al. 2006; Sasanuma et al. 2008; Wan et al. 2008). Rec114 localizes independently of other DSB proteins to the DNA and is needed for Spo11 association with hot-spot DNA (Prieler et al. 2005; Sasanuma et al. 2007; Maleki et al. 2007). Furthermore, its over-expression prevents DSB formation (Bishop et al. 1999). Rec114 as well as Mei4 interact with Rec102 and Rec104 in a yeast twohybrid assay (Arora et al. 2004; Maleki et al. 2007). It might well be that Rec102/Rec104 bridge the interaction between Rec114/Mei4/Mer2 and Spo11/Ski8.

Other proteins, which are not directly engaged in the formation of DSBs but might be needed for proper loading or activation of the recombination initiation complex might affect DSB formation. As DSBs occur mainly in already open chromatin regions, e.g. promotor regions with transcription factor mediated chromatin remodeling, any protein responsible for opening the chromatin might be involved in recruiting the recombination initiation complex (reviewed in Lichten 2008). Mentionable are also the meiosis-specific proteins Red1, Mek1, and Hop1, which associate to form the axial elements of the synaptonemal complex (SC), a tripartite structure present in many organisms to mediate pairing of homologous chromosomes (reviewed in Zickler and Kleckner 1999). As such, these three proteins form the basis for the chromatin loops of the sister chromatids. $\mathrm{redl}^{-}, \mathrm{mekl}^{-}$, or hop $1^{-}$mutants lead to DSB reduction from 5 to $15 \%$ of the wild type (Carballo et al. 2008; Mao-Draayer et al. 1996; Xu et al. 1997). This reduction implies a more supporting than essential role in DSB formation.

In the distantly related ascomycete Schizosaccharomyces pombe, 10 proteins are assumed to be required for meiotic DSB formation: Rec6, Rec7, Rec8, Rec10, Rec11, Rec12, Rec14, Rec15, Rec24, Rec25, Rec27, and Mde2 (Ponticelli and Smith 1989; De Veaux et al. 1992; Cervantes et al. 2000; Martin-Castellanos et al. 2005; Gregan et al. 2005). $S$. pombe does not possess a SC but structures similar to the axial elements, the linear elements (LinEs) are observed (Bähler et al. 1993; Lorenz et al. 2004). The proper assembly of the LinEs requires inter-dependably Rec10, Rec25, and Rec27 (Davis et al. 2008), as well as Rec8 and Rec11, the meiotic cohesins responsible for sister chromatid cohesion during meiosis I (Molnar et al. 1995; Parisi et al. 1999; Kitajima et al. 2003). LinE-associated proteins, Hop1 and Mek1, are not absolutely required but are needed for wild-type levels of DSB formation (Latypov et al. 2010).

Besides Rec12, two more $S$. pombe DSB-proteins have homologs in S. cerevisiae: Rec14 is the homolog of Ski8 
(Evans et al. 1997) and Rec7 is the homolog of Rec114

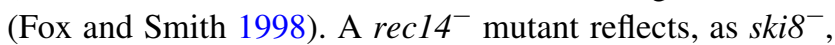
a mitotic slow-growth phenotype (Evans et al. 1997; Deutschbauer et al. 2005), which might be related to its function in RNA metabolism. Rec12's association with hot-spot DNA depends on Rec14 as well as on Rec6 (Ludin et al. 2008).

Before karyogamy, up to three Rec7 foci are formed per nucleus, as detected in cytological experiments with living cells (Molnar et al. 2001b). Later during meiosis, Rec7 foci reach a maximum in prophase I and decreases afterwards, but some foci persist until meiosis I (Molnar et al. 2001b). The formation of the prophase I foci depends on Rec10 (Lorenz et al. 2006). As rec15 ${ }^{-}$, rec $7^{-}$shows a prolonged meiosis I stage, probably due to chromosome segregation difficulties, seen in a lagging chromosome phenotype (Molnar et al. 2001a) which is also a characteristic of $m d e 2^{-}$(Gregan et al. 2005). In addition, rec $7^{-}$crosses produce homozygous diploid spores with a high frequency arising by omission of meiosis II (Molnar et al. 2001b). This phenomenon is found in rec12- (Davis and Smith. 2003), rec14- (Molnar et al. 2001a), rec15- (Doll et al. 2005), and rec $24^{-}$mutants as well (Martin-Castellanos et al. 2005). Whether this phenotype is caused by the same mechanism in all these mutants remains to be investigated.

There must be candidates for the meiotic recombination initiation complex among the remaining proteins in the above list. To further characterize the interplay among potential candidates of the $S$. pombe meiotic initiation complex, we employed a yeast two-hybrid all-against-all matrix of the proteins mentioned above. Here, we present three new interactions, Rec7 with Rec24, Rec12 with Rec14, and Rec15 with Mde2, respectively.

\section{Materials and methods}

Culture methods and yeast strains

Media and general methods for S.cerevisiae were used as described in (Ausubel et al. 2009). Media and general methods for S. pombe are described in (Gutz et al. 1974; Moreno et al, 1991). Synthetic medium, EMM with 2\% glucose, and EMM without nitrogen source (EMM-N) with $1 \%$ glucose were described in (Nurse et al. 1976). Supplements were added to a final concentration of $0.1 \%$, where appropriate. Construction of rec7HA3::kan ${ }^{R}$ was done by the PCR-based method after Bähler with primers \#SIL9 and \#SIL10 (Table S3) and plasmid pFA6a-HA3 (Bähler et al. 1998). Similarly, rec24TAP4::kan ${ }^{R}$ was constructed with primers \#SIL1 and \#SIL2 and pFA6aTAP4 (P2021, K. Gould). After sequencing of the constructs, both Rec7HA3 and Rec24TAP4 were tested for functionality. In crosses homozygous for $\mathrm{rec} 7 \mathrm{HA}: \mathrm{kan}^{R}$ and rec24TAP4:: $\mathrm{kan}^{R}$ spore viability was tested on YEA medium under the tetrad microscope by visually counting non-germinating spores versus appearing micro colonies.

Construction of diploid strains

A diploid $h^{-} / h^{-}$strain expressing epitope-tagged Rec7HA3 and/or Rec24TAP4 was constructed by scoring for a mitotic crossover between the mating-type region and the centromere on chromosome II of a $h^{+} / h^{-}$diploid strain. This strain was procured by mating a haploid pat1-114 ade6M210 lys7-2 strain with a haploid pat1-114 ade6-M216 leu2-120 strain for $12 \mathrm{~h}$ on a SPO plate. The ade6-M210 and ade6-M216 alleles on chromosome III complement each other, whereas the lys7-2 and leu2-120 markers on chromosome I are closely linked, reducing the possibility of a mitotic crossover event between them. Cell material was collected, resuspended in water, and plated on MMA plates. After 4 days at $25^{\circ} \mathrm{C}$, large colonies were picked and re-isolated on MMA plates. The absence of sporulation was investigated by iodine staining after 3 days growth on MEA plates. The mating-type of the non-sporulating diploids was verified with back-crossings to tester strains $975 h^{+}$or $972 h^{-}$.

\section{Yeast two-hybrid system}

The PCR-based recombinational cloning method after Hudson et al. (1997) was used to integrate the intronless gene-of-interest into the yeast two-hybrid ( $\mathrm{Y} 2 \mathrm{H})$ vectors pOAD and pOBD, respectively, resulting in a fusion between either sequences of the activation- or the binding domain of the GAL4 gene with sequences of gene-ofinterest (free gene-of-interest $\mathrm{C}$-terminus). Primers and templates used for PCR-cloning are listed in Table S1 and primer sequences in Table S3. The rec7 point mutation (rec7F325A, TTC to GCC) was introduced by PCR with a long primer containing the base substitution and the resulting PCR fragment was cloned as described above (Table S1, S3). The rec12 point mutations (rec12Q308A, CAG to GCG, and rec12R309A, GGA to GCA, respectively) were introduced by fusion PCR using primers with homologous sequence over the base substitutions, and the resulting PCR fragment was cloned as described above (Table S1, S3). After recombinational transformation into S. cerevisiae strains PJ694A or PJ694 $\alpha$ (Table 1; James et al. 1996), plasmids were isolated (QIAprep Spin Miniprep Kit) and sequence-confirmed. Yeast two-hybrid analysis was performed in diploid cells which were derived from mated $S$. cerevisiae strains PJ694 $\alpha$ and PJ694A (Table 1), transformed with sequence-checked pOBD or pOAD derivatives. Expression of three reporter genes 
Table 1 Strain list

\begin{tabular}{|c|c|c|}
\hline Yeast strain & Genotype & Reference \\
\hline \multicolumn{3}{|l|}{ S. cerevisiae } \\
\hline PJ69-4a & 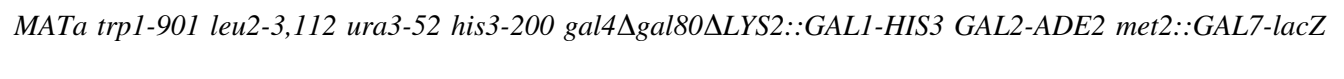 & $\begin{array}{l}\text { James et al. } \\
\text { (1996) }\end{array}$ \\
\hline PH69-4 $\alpha$ & 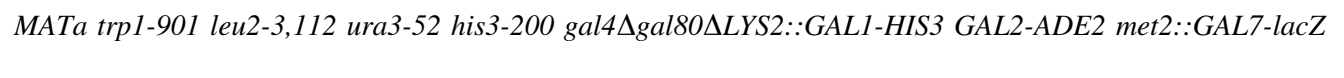 & $\begin{array}{l}\text { James et a.1 } \\
\text { (1996) }\end{array}$ \\
\hline \multicolumn{3}{|l|}{ S. pombe } \\
\hline $153-6133$ & $h^{+}$lys $1-131$ ade6-M26 & $\begin{array}{l}\text { Berne } \\
\text { collection }\end{array}$ \\
\hline $153-6136$ & $h^{-}$lys $1-131$ ade6-469 & $\begin{array}{l}\text { Berne } \\
\text { collection }\end{array}$ \\
\hline KLY399 & $h^{-}$lys1-131 ade6-469 rec124::hyg ${ }^{R}$ & This study \\
\hline KLY402 & $h^{+}$lys $1-131$ ade6-M26 rec12 $1::$ hyg $^{R}$ & This study \\
\hline KLY410 & $h^{-}$lys $1-131$ ade6-469 ura4-D18 rec74::ura4 & This study \\
\hline KLY414 & $h^{+}$lys $1-131$ ade6-M26 ura4-D18 rec74::ura4 & This study \\
\hline SILY117 & 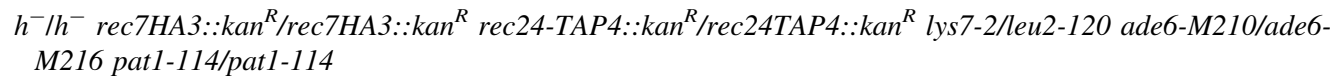 & This study \\
\hline SILY123 & $h^{-} / h^{-}$rec7HA3::kan $/$rec7HA3::kan ${ }^{R}$ lys7-2/leu2-120 ade6-M210/ade6-M216 pat1-114/pat1-114 & This study \\
\hline
\end{tabular}

( $\mathrm{P}_{G A L 2}-A D E 2, \mathrm{P}_{G A L 2}-H I S 3$, and $\mathrm{P}_{G A L 2}$-lacZ) was assayed: growth on drop-out minimal media missing leucine, tryptophane, and adenine; growth on drop-out minimal media missing leucine, tryptophane, and histidine, but replenished with $25 \mathrm{mM} 3$-aminotriazole (3-AT); and $\beta$-galactosidase activity assayed in permeabilized cells (Ludin et al. 1998).

\section{S. pombe plasmid constructions}

pSIL2 was constructed in several steps: first, pMR3, a pREP41 (Basi et al. 1993) derivate containing a thiaminerepressible, myc epitope-tagged rec12 in the Sal I site, was used to amplify the $n m t 1$-promotor sequence with primers \#SIL81 and \#SIL82, producing PstI and XhoI restriction site overhangs. A second PCR amplification with primers \#SIL83 and \#SIL84 and pMR3 produced a fragment containing 13 myc epitopes followed by nmtl-terminator sequences with $\mathrm{XhoI}$ and $K p n \mathrm{I}$ restriction site overhangs. The two fragments were fused by PCR amplification using primers \#SIL81 and \#SIL84 and sequence homology over the $X h o$ I restriction site. The resulting PCR fragment was ligated into the KpnI and PstI restriction sites of pYC36 (Chikashige et al. 2004) to form pSIL2. S. pombe genes were PCR amplified using a forward primer with a XhoI restriction site overhang and a reverse primer with a SalI and a XhoI restriction site overhang (Table S2, S3) with genomic DNA (rec7, recl2) or $\mathrm{Y} 2 \mathrm{H}$ plasmid DNA (rec7F325A, rec12Q308A, and rec12R309A) as target sequence. XhoI digested PCR fragments were ligated into XhoI digested pSIL2 to create myc epitope-tagged constructs (e.g. pSIL2-Rec $7_{m y c}$ ) or XhoI, SalI digested PCR fragments were ligated into XhoI digested pSIL2 to create untagged constructs with a stop codon $21 \mathrm{bp}$ after the last gene-specific codon (e.g. pSIL2-Rec7). All constructs were sequenced before transformation.

Intragenic recombination assay

pSIL 2 or pSIL 2 derivatives were transformed into $h^{+}$ade6M26 lys 1-131 strains (with or without deletion of rec7 or rec12, respectively) and integrated at the lys 1 locus by homologous recombination between the C-terminal truncated lysl gene on pSIL2 and lys1-131. Transformants, which were able to grow on GMA+ade media were crossed with strains of the background $h^{-}$ade6-469 lys $1^{+}:: p$ SIL2 with or without deletion of rec7 or recl2 by the following procedure: parental strains were grown to stationary phase in EMM+ade medium for at least $48 \mathrm{~h}$. As much as $500 \mu \mathrm{l}$ of each culture was mixed with the respective partner culture, briefly centrifuged, and the cell pellet washed by vortexing extensively with $500 \mu 150 \mathrm{mM}$ Na-phosphate at pH 7.0. Cells were again centrifuged and resuspended totally in $50 \mu \mathrm{l} 50 \mathrm{mM} \mathrm{Na-phosphate} \mathrm{at}$ $\mathrm{pH}$ 7.0. As much as $5 \mu \mathrm{l}$ of this cell suspension was spotted on a SPO plate or on SPO+thiamine $(2 \mu \mathrm{M})$ plate and incubated for $48 \mathrm{~h}$ at $25^{\circ} \mathrm{C}$. Crossing material was then scratched from the plate and incubated for $4 \mathrm{~h}$ in $500 \mu \mathrm{l}$ water containing $0.2 \%$ glusulase (Helix pomatia Juice. PALL Life Sciences) and $0.05 \%$ lysing enzyme (Sigma $\mathrm{L}-1412)$ at $30^{\circ} \mathrm{C}$. The spore suspension was centrifuged and the pellet was resuspended in $500 \mu \mathrm{l} 50 \mathrm{mM}$ Na-phosphate at pH 7.0. A $5 \mu \mathrm{l}$ of this spore suspension, or 
ten-fold dilutions, was spotted on GMA and GMA+adenine plates and growth was scored after 4 days at $30^{\circ} \mathrm{C}$. Recombination analysis was repeated at least three times with individual $\mathrm{lys}^{+}$transformants. Homozygous wild-type crosses, heterozygous mutant crosses, and homozygous mutant crosses were always performed in parallel. Spore viability analysis (Rothenberg et al. 2009) of all crosses listed in Figs. 3 and 7 is given in Table S4.

\section{Western blot}

Protein extracts (Caspari et al. 2000) were separated on $10 \%$ SDS polyacrylamide gels and blotted on PVDF membranes (Immobilon, Millipore) in a wet blot chamber (BioRad) for $1 \mathrm{~h} 15 \mathrm{~min}$ at $400 \mathrm{mAmp}$. After over night blocking at $4{ }^{\circ} \mathrm{C}$ with $5 \%$ milk in PBS-T $(20 \mathrm{mM}$ phosphate, $150 \mathrm{mM} \mathrm{NaCl}$, and $0.05 \%$ Tween), the membrane was probed with one of the following antibodies: monoclonal mouse anti-HA HRP coupled (12CA5, Roche) at a dilution of $1 / 400$ or monoclonal mouse anti-HA (12CA5, Roche) at a dilution of 1/1,000 and polyclonal rabbit antimouse HRP coupled (DAKO) for detection of Rec7HA, polyclonal rabbit anti-HRP antibody in combination with HRP (PAP, DAKO) at a dilution of $1 / 15,000$ for detection of Rec24TAP4.

\section{Co-immunoprecipitation}

Diploid strains (Table 1) were grown to an $\mathrm{OD}_{595}$ of 0.4 in EMM at $25^{\circ} \mathrm{C}$. The cells were washed once with water and resuspended in EMM-N. After $16 \mathrm{~h}$ of nitrogen starvation cells were arrested in G1. Meiosis was induced by a temperature shift to $34^{\circ} \mathrm{C}$ after the addition of $\mathrm{NH}_{4} \mathrm{Cl}$ to a final concentration of $0.5 \mathrm{~g} / \mathrm{l}$. At each timepoint from 0 to $8 \mathrm{~h}$, $1 \mathrm{ml}$ of cell culture was taken washed once with $\mathrm{H}_{2} \mathrm{O}$ then resuspended in $1 \mathrm{ml} 70 \% \mathrm{EtOH}$ for DAPI and FACS analysis. At time points $0 \mathrm{~h}$ (T0) and $3.5 \mathrm{~h}$ (T3.5) $175 \mathrm{ml}$ cell culture was centrifuged for $3 \mathrm{~min}$ at 3,000 rpm (Eppendorf 5417C), washed with $175 \mathrm{ml}$ PBS (20 mM phosphate, $150 \mathrm{mM} \mathrm{NaCl}$ ) with freshly added phenylmethylsulfonyl fluoride (PMSF) to a final concentration of $1 \mathrm{mM}$, and centrifuged again. The cell pellet was resuspended in $300 \mu \mathrm{l}$ PBS with freshly added PMSF, protease inhibitors (Complete Protease Inhibitor Cocktail, EDTA-free, Roche) and phosphatase inhibitors (PhosSTOP Phosphatase Inhibitor Cocktail, Roche). A ceramic mortar and pestle were cooled with liquid $\mathrm{N}_{2}$. Thick cell suspension was pipetted into the mortar filled with liquid $\mathrm{N}_{2}$ and then pestled for at least 5 min under constant addition of $\mathrm{N}_{2}$. The cell powder was stored at $-80^{\circ} \mathrm{C}$ until further use. The cell powder was resuspended in $600 \mu \mathrm{l}$ lysis buffer $(50 \mathrm{mM}$ Tris- $\mathrm{HCl}$ pH 8.0, $150 \mathrm{mM} \mathrm{NaCl}, 8.7 \%$ Glycerol, $1 \mathrm{mM}$ PMSF, protease, and phosphatase inhibitors) and centrifuged for $5 \mathrm{~min}$ at $4{ }^{\circ} \mathrm{C}$ in a micro centrifuge at maximal speed. The supernatant was transferred into a new eppendorf tube and a centrifugation of $15 \mathrm{~min}$ at maximal speed followed. The supernatant was transferred into a new eppendorf tube and if needed was adjusted to $1,025 \mu 1$ with lysis buffer (whole cell extract, WCE). As much as $25 \mu \mathrm{l}$ WCE was mixed with $25 \mu 1$ 2x Lämmli buffer (125 mM Tris-HCl, 20\% glycerol, $4 \%$ SDS, $0.02 \%$ Bromphenol blue, $\mathrm{pH} 6.8$ ), boiled and stored at $-20^{\circ} \mathrm{C}$ (Input). IgG sepharose (IgG Sepharose ${ }^{\mathrm{TM}} 6$ Fast Flow, GE Healthcare) was pre-washed at $4^{\circ} \mathrm{C}$ by resuspension and centrifugation $(1,000 \mathrm{rpm}$ in a micro centrifuge) five times with $50 \mathrm{mM}$ Tris- $\mathrm{HCl}, 150 \mathrm{mM}$ $\mathrm{NaCl}, 0.05 \%$ Tween, and twice with lysis buffer. A $30 \mu \mathrm{l}$ of the pre-washed sepharose matrix was incubated with $1 \mathrm{ml}$ of WCE for $2 \mathrm{~h}$ at $4^{\circ} \mathrm{C}$ on a rotating wheel. PMSF was added to a final concentration of $1 \mathrm{mM}$ every $30 \mathrm{~min}$. The sepharose matrix was washed 6 times with $1 \mathrm{ml}$ lysis buffer, resuspended in $50 \mu 12 x$ Lämmli buffer, and boiled and stored at $-20^{\circ} \mathrm{C}$.

\section{Results and discussion}

Yeast two-hybrid analysis among putative members of the meiotic recombination initiation complex

To test for physical interactions between the fission yeast DSB proteins, we carried out a yeast two-hybrid $(\mathrm{Y} 2 \mathrm{H})$ assay in pair-wise combinations. We cloned cDNA sequences of rec6, rec 7 , rec10, rec 12 , recl4, rec 15 , mde2, rec 24 , and rec 25 behind the GAL4 DNA-binding domain or the GALA activation domain in the vectors pOBD or pOAD, respectively (see Materials and methods). We failed after many attempts to clone rec27 cDNA and left it out for the analysis. We also included in the $\mathrm{Y} 2 \mathrm{H}$ assay rec 23 and rec26, the gene products of which were reported to co-immunoprecipitate in $S$. pombe. They served us as an interaction control (Chikashige et al. 2006). rec23 and rec26 mutants also showed decreased DSB formation, but were found to be involved in bouquet formation, thus their synonyms bqt2 and bqt1, respectively.

The diploid $\mathrm{Y} 2 \mathrm{H}$ strain PJ69-4 contains three reporter genes under the control of different $G A L$ promotors: $\mathrm{P}_{G A L 2^{-}}$ ADE2, $\mathrm{P}_{G A L 1}-H I S 3$, and $\mathrm{P}_{G A L 7}$-lacZ. The auxotrophic reporter genes were used for an all-against-all $\mathrm{Y} 2 \mathrm{H}$ analysis. If an interaction is apparent, growth on media lacking adenine, or on media lacking histidine but replenished with 3 -aminotriazole as an inhibitor of the sparsely expressed HIS3 gene product, is feasible. We confirmed the interaction between Rec23/Bqt2 and Rec26/Bqt1 in both construct combinations, Gal4BD-Rec23 with Gal4AD-Rec26 and Gal4AD-Rec23 with Gal4BD-Rec26, respectively (Fig. 1). Besides this control interaction, three novel interactions 


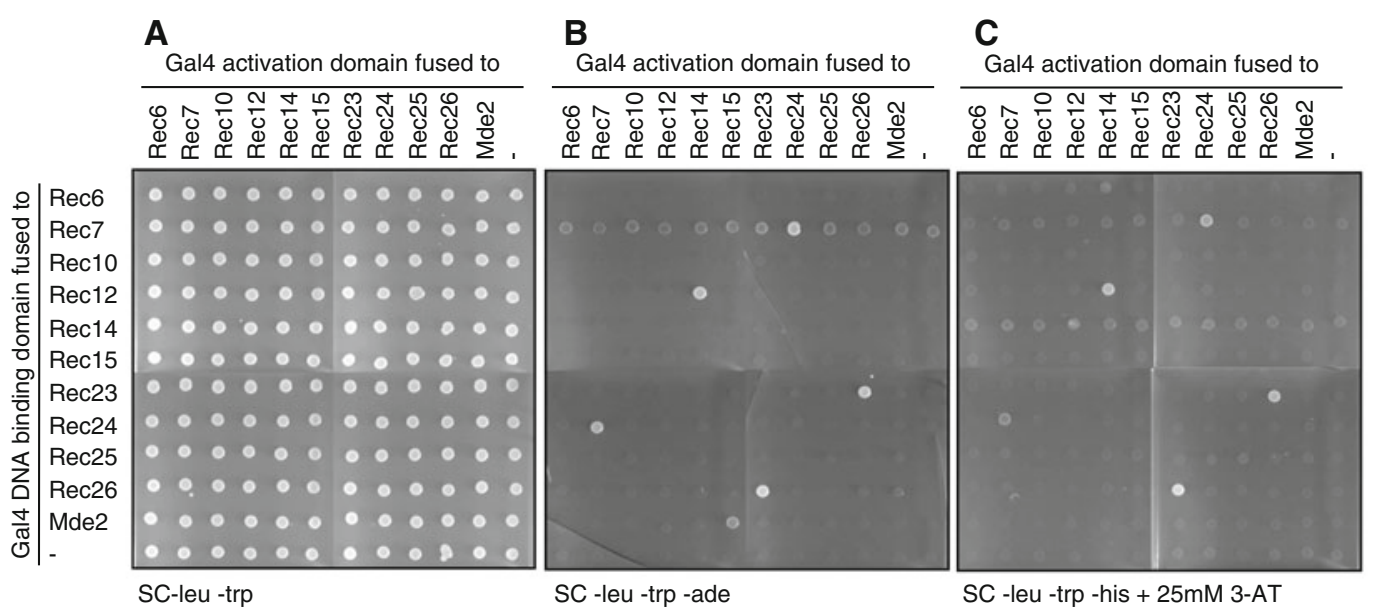

Fig. 1 Matrix of yeast two-hybrid interaction analysis of early meiotic recombination proteins. Gal4 activation domain or DNA binding domain fusions to $S$. pombe proteins involved in early meiosis were assayed in the $S$. cerevisiae yeast two-hybrid strain PJ69-4 in pairwise combinations for growth of synthetic complete media lacking leucine and tryptophan (SC leu-trp) for the presence of both

were found; we detected an interaction between $\operatorname{Rec} 7$ and Rec24: the expression of both combinations stimulated $\mathrm{P}_{G A L 2}-A D E 2$ and $\mathrm{P}_{G A L 1}-H I S 3$ expression. Gal4BD-Rec7 was showing a mild self-activation phenotype when tested for expression of $\mathrm{P}_{G A L 2}-A D E 2$. Similarly, the Rec7 homolog in S. cerevisiae, Rec114 activated a lacZ reporter when fused to a DNA-binding domain (Arora et al. 2004). Another interaction was detected between Rec12 and Rec14, although only the combination Gal4BD-Rec12 with Gal4AD-Rec14 stimulated expression of $\mathrm{P}_{G A L 2}-A D E 2$ and $\mathrm{P}_{G A L 1}$-HIS3. Finally, an interaction between Mde2 and Rec15 was found, but only the combination Gal4BD-Mde2 with Gal4AD-Rec15 stimulated transcription of the $\mathrm{P}_{G A L 2^{-}}$ $A D E 2$ reporter gene. The interactions between Rec7 and Rec24 and between Rec12 and Rec14 were studied in more detail. Although the interaction was seen only in one construct combination, it was interesting to see whether similar interaction parameters applied to Rec12-Rec14 as it was shown for S. cerevisiae Spo11-Ski8 (Arora et al, 2004). The interaction of Mde2 with Rec15 was not further characterized because the weak activation of the $\mathrm{P}_{G A L 2}-A D E 2$ reporter gene could neither be confirmed with the $\mathrm{P}_{G A L 1}-H I S 3$ (Fig. 1c) nor the $\mathrm{P}_{G A L 7}-l a c Z$ reporter gene (data not shown). Nevertheless, sterical hindrances of Gal4 fusion constructs as well as fission yeast, meiosisspecific changes in the post-translational protein modification might limit the score in this $\mathrm{Y} 2 \mathrm{H}$ interaction analysis. fusion constructs (a), on synthetic complete media lacking adenine, leucine, and tryptophan (SC ade-leu-trp) for expression of the $\mathrm{P}_{G A L 2}-A D E 2$ reporter (b), and on synthetic complete media lacking histidine, leucine, and tryptophan (SC his-leu-trp) for expression of the $\mathrm{P}_{G A L 2}-H I S 3$ reporter (C). "_" stands for empty vector

Rec12/Rec14 interaction resembles Spo11/Ski8 interaction

It was previously shown that amino acid changes in the C-terminus of Spo11, Q376A, or RE377AA reduce the Y2H interaction with Ski8 vigorously (Arora et al. 2004). In addition, these amino acid changes trigger a recombination defect similar to spo $11 \Delta$. Both amino acids, glutamine at position 308 and arginine at position 309 are conserved in Rec12. In a Y2H analysis with Gal4BD-Rec12Q308A and Gal4AD-Rec14, a reduced interaction was detected with the $\mathrm{P}_{G A L 2}-A D E 2$ reporter gene; whereas no interaction was found with the $\mathrm{P}_{G A L 1}-H I S 3$ and the $\mathrm{P}_{G A L 7}$-lacZ reporter genes (Fig. 2; Table 2). The interaction between Gal4BDRec12R309A and Gal4AD-Rec14 was completely abolished with all three reporters (Fig. 2; Table 2). A hydrophobic amino acid patch in Ski8 is involved in the interaction with Spo11 and especially phenylalanine at position 59 seems to be crucial, as determined by crystal structure (Cheng et al. 2004).

At the equivalent position 57 in Rec14 a proline is located instead of a phenylalanine. Nevertheless, we wondered if the N-terminus of Rec14 is involved in the interaction with Rec12. A Y2H analysis with Gal4BDRec12 and Gal4AD-Rec14 $\Delta \mathrm{N}$, missing the N-terminal 61 amino acids, revealed a loss of interaction based on the lack of activation with all three reporter genes (Fig. 2; Table 2). 


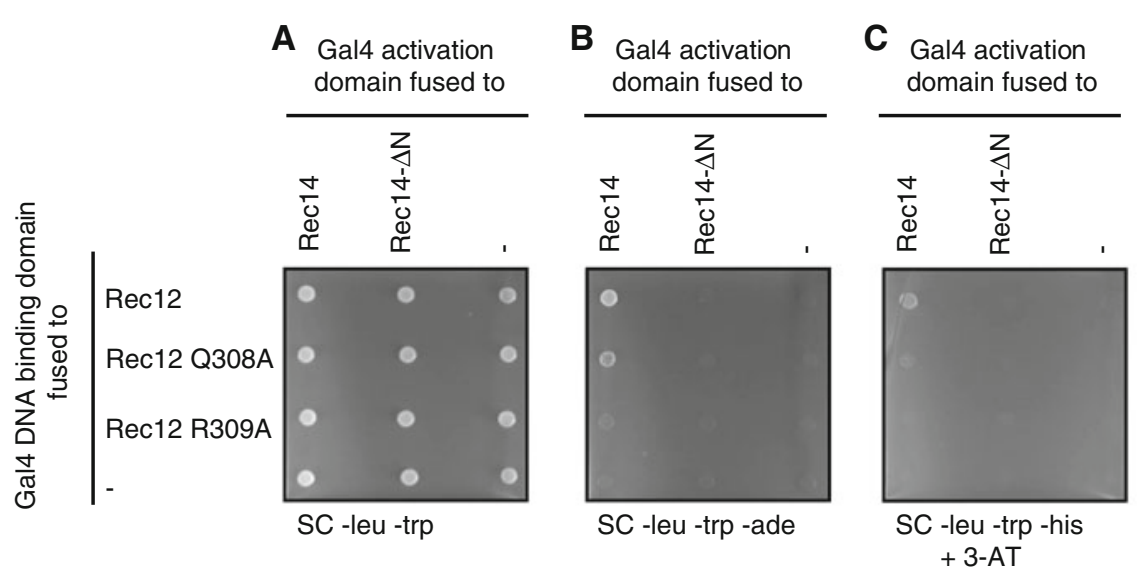

Fig. 2 Yeast two-hybrid interaction analysis of Rec12 and Rec14. Gal4 DNA-binding domain fusions to Rec12, Rec12Q308A, or Rec12R309A in combination with Gal4 activation domain fusions to Rec14 or Rec14 $\Delta \mathrm{N}$ were assayed for growth on synthetic complete media lacking leucine and tryptophan (SC leu-trp) for the presence of

Table $2 \mathrm{Y} 2 \mathrm{H}$ interaction of Rec12 and Rec14 domains analyzed with the $\mathrm{P}_{G A L 7}$-lac $Z$ reporter

\begin{tabular}{|c|c|c|c|}
\hline pOAD & pOBD & $\beta$-gal activity ${ }^{\mathrm{a}}$ & $\mathrm{SEM}^{\mathrm{b}}$ \\
\hline $\operatorname{Rec} 14$ & $\operatorname{Rec} 12$ & 6.6 & 1 \\
\hline Rec14 & Rec12Q308A & 0.2 & 0.2 \\
\hline $\operatorname{Rec} 14$ & Rec12R309A & $<0.1$ & \\
\hline Rec14 & - & 1.0 & 0.4 \\
\hline $\operatorname{Rec} 14 \Delta \mathrm{N}$ & $\operatorname{Rec} 12$ & $<0.1$ & \\
\hline $\operatorname{Rec} 14 \Delta N$ & Rec12Q308A & $<0.1$ & \\
\hline $\operatorname{Rec} 14 \Delta N$ & Rec12R309A & $<0.1$ & \\
\hline $\operatorname{Rec} 14 \Delta N$ & - & 0.9 & 0.3 \\
\hline- & $\operatorname{Rec} 12$ & $<0.1$ & \\
\hline- & Rec12Q308A & $<0.1$ & \\
\hline - & Rec12R309A & $<0.1$ & \\
\hline
\end{tabular}

${ }^{a}$ The mean $\beta$-galactosidase activity from 3 to 10 independent transformants is given in Miller units

b SEM stands for standard error of the mean

Interaction loss between Rec12Q308A or Rec12R309A and Rec14 leads to recombination deficiency in $S$. pombe

We wondered whether the amino acid substitutions Q308A and R309A in Rec12, which were responsible for the loss of interaction with Rec14, lead to meiotic recombination deficiency in $S$. pombe. We integrated rec12, rec12Q308A, and rec12R309A, controlled from a thiamine-repressible promotor, into a rec $12 \Delta$ strain and asked whether they can complement the rec $12 \Delta$ meiotic recombination defect. In a qualitative recombination assay, we measured intragenic recombination between ade6-M26 and ade6-469 in crosses heterogenous for the integrated rec12 construct ("Materials both fusion constructs (a), synthetic complete media lacking adenine, leucine, and tryptophan (SC ade-leu-trp) for the expression of the $\mathrm{P}_{G A L 2}-A D E 2$ reporter (b), and on synthetic complete media lacking histidine, leucine, and tryptophan (SC his-leu-trp) for expression of the $\mathrm{P}_{\text {GAL2 }}$ HIS3 reporter (C). "-" stands for empty vector

and methods", Fig. 3). The same recombination proficiency as in a heterozygous rec $12 \Delta$ cross was seen in crosses with integrated rec12, independently of the thiamine condition. Obviously, Rec12 protein is not a limiting factor for proper recombination initiation as also suggested from Western blot analysis by the high amount of free Rec12 protein in a meiotic time course when probed for bound oligonucleotides (Rothenberg et al. 2009). In crosses with rec12Q308A or rec12R309A integrations, few adenine prototrophs were detected. Spore viability of these crosses was not significantly different from the spore viability of the homozygous rec $12 \Delta$ cross (Table S4). Western blot analysis confirmed that myc epitope tagged Rec12Q308A and Rec12R309A were expressed (Figure S1).

From these results we conclude that amino acid Q308 and R309 in Rec12 and the N-terminus of Rec14 are required for mutual interaction. This interaction is essential for proper recombination levels. The fact that homologous amino acids/domain in the distantly related yeasts are required for this interaction shows not only phylogenetical, but also a structural conservation of part of the DSB machine.

The C-terminus of Rec7 interacts with the $\mathrm{N}$-terminus of $\operatorname{Rec} 24$

To find out which part of Rec7 participates in the physical interaction with Rec24, Y2H plasmids were constructed with one out of four Rec7 sequence parts, Rec7A to Rec7D (Table S1, S3). A Y2H interaction analysis was performed between these partial Rec7 proteins and full length Rec24 in both combinations, e.g. Gal4BD-Rec7A with Gal4AD-Rec24 


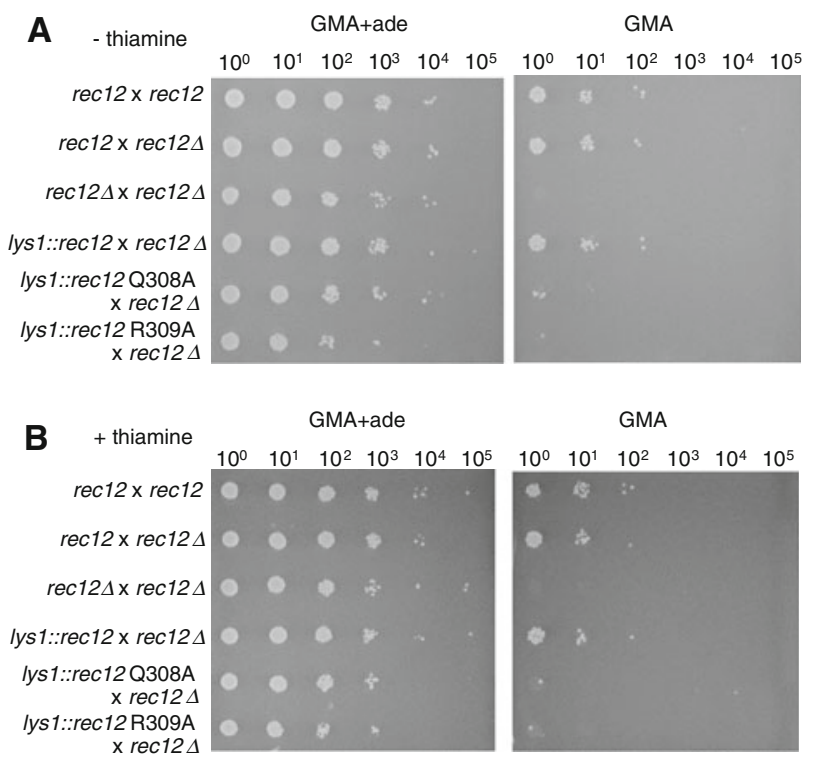

Fig. 3 Amino acid changes in Rec12, Q308A and R309A, lead to a recombination defect. Undiluted and tenfold dilutions of spore suspensions from derepressed (a, SPO media) or repressed conditions (b, SPO media with thiamine) of homozygous rec12, heterozygous

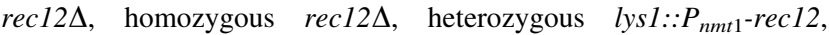
heterozygous $l y s 1:: P_{n m t 1}-r e c 12 Q 308 A$, and heterozygous $l y s 1:: P_{n m t 1}{ }^{-}$ rec12R309A crosses, grown on minimal media containing adenine (GMA+ade, left panel) or on minimal media without adenine (GMA, right panel)

and Gal4BD-Rec24 with Gal4AD-Rec7A. $\mathrm{P}_{G A L 2}-A D E 2$, $\mathrm{P}_{G A L 1}-H I S 3$ (Fig. 4), and $\mathrm{P}_{G A L 7}$-lacZ expressions (Table 3) were stimulated only when Rec24 was combined with Rec7D. When Gal4BD- or Gal4AD-construct fused to different parts of Rec24 (A to D) is expressed together with Gal4AD-Rec7 or Gal4BD-Rec7, only Rec24A showed a Y2H interaction with Rec7 (Fig. 4; Table 3).

So far, no Rec24 orthologs were found. However, a multiple sequence alignment (ClustalX; Thompson et al. 1994) of Rec7 with orthologs found among sequenced ascomycete genomes pointed toward a conserved phenylalanine at position 325 in part D of Rec7 (Fig. 5). Changing this phenylalanine to alanine impaired the interaction of Gal4BD-Rec7F325A with Gal4ADRec24 and Gal4AD-Rec7F325A with Gal4BD-Rec24, as seen with all three reporter genes (Fig. 4; Table 3).

From these results we conclude that the C-terminus of Rec7, especially the phenylalanine at position 325 , and the $\mathrm{N}$-terminus of Rec24 are crucial for the interaction between these proteins.

\section{Rec7 interacts with Rec24 in S. pombe}

To demonstrate that Rec7 and Rec24 interact during $S$. pombe meiosis, we performed co-immunoprecipitation
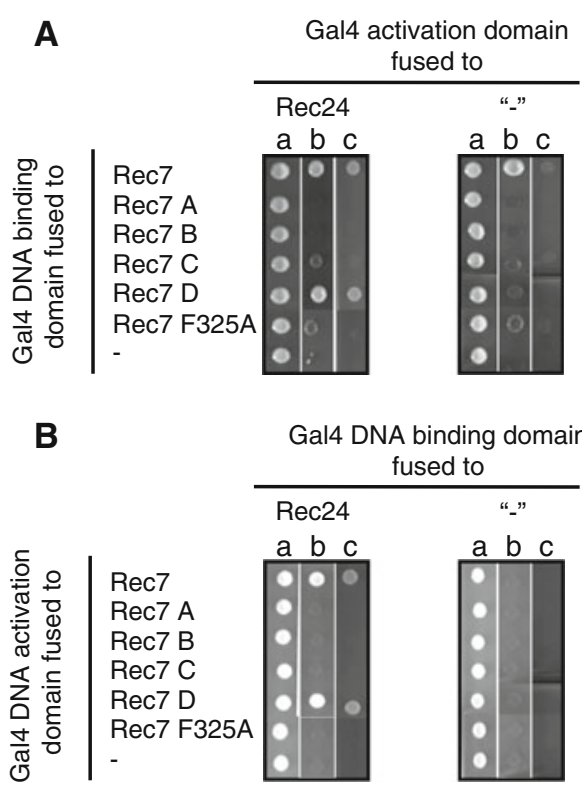

Gal4 DNA binding domain

fused to
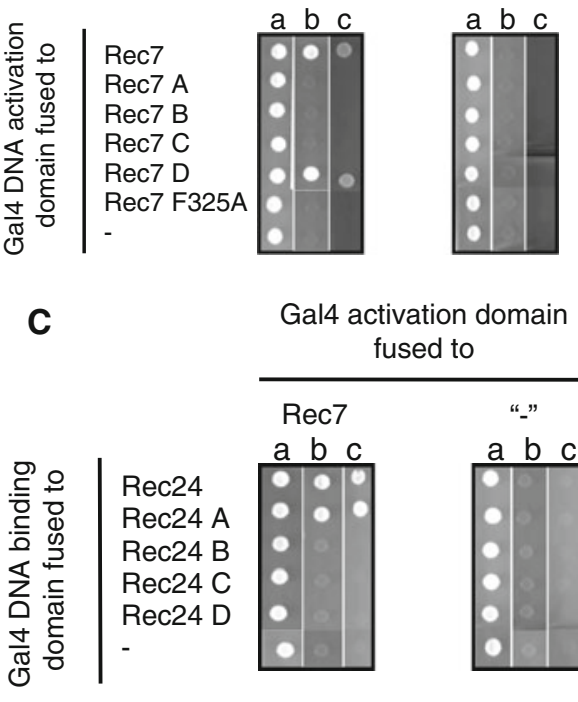

Gal4 activation domain fused to
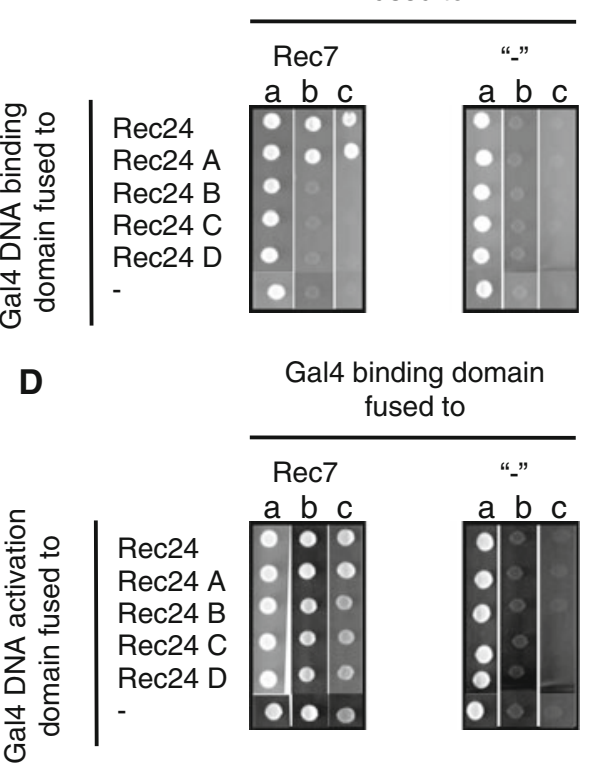

Fig. 4 Yeast two-hybrid interaction analysis of Rec7 and Rec24 domains. Gal4 DNA binding domain (a) or activation domain fusions (b) to Rec7, Rec7A (amino acids: 1-87), Rec7B (80-175), Rec7C (168-263), Rec7D (256-340), or Rec7F325A were assayed with Gal4 activation domain or Gal4 DNA binding domain fusions to Rec24 on synthetic complete media lacking leucine and tryptophan ( $a$, SC leu-trp), synthetic complete media lacking adenine, leucine, and tryptophan ( $b, \mathrm{SC}$ ade-leu-trp), and synthetic complete media lacking histidine, leucine, and tryptophan ( $c, \mathrm{SC}$ -his -leu -trp) for expression of the $\mathrm{P}_{G A L 2}-A D E 2$ and $\mathrm{P}_{G A L 2}-H I S 3$ reporters. Similarly, Gal4 DNA binding domain (c) or activation domain fusions (d) to Rec24, Rec24A (amino acids: 1-112), Rec24B (105-180), Rec24C (174-264), and Rec24D (257-357) were assayed with Gal4 activation domain or Gal4 DNA binding domain fusions to $\operatorname{Rec} 7$ for growth on the same media $(a-c)$."-” stands for empty vector 
Table 3 Y2H interaction of Rec7 and Rec24 domains analyzed with the $\mathrm{P}_{G A L 7}-$ lac $Z$ reporter

\begin{tabular}{|c|c|c|c|}
\hline pOAD- & pOBD- & $\beta$-gal activity ${ }^{\mathrm{a}}$ & $\mathrm{SEM}^{\mathrm{b}}$ \\
\hline $\operatorname{Rec} 24$ & $\operatorname{Rec} 7$ & 24.4 & 3.5 \\
\hline $\operatorname{Rec} 24$ & Rec7A & $<0.1$ & \\
\hline $\operatorname{Rec} 24$ & Rec7B & $<0.1$ & \\
\hline $\operatorname{Rec} 24$ & Rec7C & 4.3 & 0.8 \\
\hline $\operatorname{Rec} 24$ & Rec7D & 15.5 & 1.4 \\
\hline $\operatorname{Rec} 24$ & Rec7F325A & 0.2 & 0.1 \\
\hline $\operatorname{Rec} 24$ & - & 0.2 & 0.1 \\
\hline- & Rec7 & 2.2 & 0.6 \\
\hline- & Rec7A & $<0.1$ & \\
\hline- & Rec7B & $<0.1$ & \\
\hline- & Rec7C & 3.1 & 0.8 \\
\hline- & Rec7D & 0.3 & 0.2 \\
\hline- & Rec7F325A & 0.1 & 0.1 \\
\hline Rec7 & $\operatorname{Rec} 24 \mathrm{~A}$ & 61.5 & 11.3 \\
\hline Rec7 & $\operatorname{Rec} 24 B$ & $<0.1$ & \\
\hline Rec7 & $\operatorname{Rec} 24 \mathrm{C}$ & 0.2 & 0.2 \\
\hline Rec7 & Rec24D & 0.1 & 0.1 \\
\hline- & $\operatorname{Rec} 24 \mathrm{~A}$ & 0.1 & 0.1 \\
\hline- & $\operatorname{Rec} 24 B$ & $<0.1$ & \\
\hline- & $\operatorname{Rec} 24 \mathrm{C}$ & $<0.1$ & \\
\hline- & Rec24D & 0.5 & 0.3 \\
\hline Rec7 & $\operatorname{Rec} 24$ & 10.9 & 2.5 \\
\hline Rec7A & $\operatorname{Rec} 24$ & $<0.1$ & \\
\hline Rec7B & $\operatorname{Rec} 24$ & $<0.1$ & \\
\hline Rec7C & $\operatorname{Rec} 24$ & $<0.1$ & \\
\hline Rec7D & $\operatorname{Rec} 24$ & 60.2 & 14.2 \\
\hline Rec7F325A & $\operatorname{Rec} 24$ & $<0.1$ & \\
\hline- & $\operatorname{Rec} 24$ & $<0.1$ & \\
\hline Rec7 & - & 0.5 & 0.2 \\
\hline Rec7A & - & 0.2 & 0.1 \\
\hline $\operatorname{Rec} 7 \mathrm{~B}$ & - & 0.5 & 0.3 \\
\hline Rec7C & - & 0.5 & 0.4 \\
\hline Rec7D & - & 0.2 & 0.1 \\
\hline Rec7F325A & - & 0.1 & 0.1 \\
\hline $\operatorname{Rec} 24 \mathrm{~A}$ & $\operatorname{Rec} 7$ & 40.4 & 14.9 \\
\hline Rec24B & $\operatorname{Rec} 7$ & 1.4 & 0.4 \\
\hline $\operatorname{Rec} 24 \mathrm{C}$ & $\operatorname{Rec} 7$ & 1.1 & 0.2 \\
\hline Rec24D & Rec7 & 1.9 & 0.6 \\
\hline $\operatorname{Rec} 24 \mathrm{~A}$ & - & 0.6 & 0.3 \\
\hline Rec24B & - & 0.4 & 0.3 \\
\hline $\operatorname{Rec} 24 \mathrm{C}$ & - & 0.2 & 0.1 \\
\hline Rec24D & - & 0.1 & 0.1 \\
\hline
\end{tabular}

${ }^{a}$ The mean $\beta$-galactosidase activity from 3 to 10 independent transformants is given in Miller units

b SEM stands for standard error of the mean experiments with tagged proteins from pat1-114 meiotic cell samples. Inducing meiosis in a pat1-114 mutant strain has the advantage of high synchronicity (Beach 1985), but the disadvantage of a chromosome segregation defect in the first meiotic division (Yamamoto and Hiraoka 2003). However, it has been used systematically for the timing of early meiotic events including DSB formation (Cervantes et al. 2000; Young et al. 2002). Functional Rec7HA3 and Rec24TAP4 were expressed in a $h^{-} / h^{-}$pat1-114/pat1-114 diploid strain (Table 1, "Materials and methods") and Rec24TAP4 was immuno-precipitated at time points 0 or 3 $\mathrm{h}$ after meiotic start (for FACS analysis, see Figure S2), utilizing the affinity of the Protein A epitope to human immunoglobulin. As shown in Fig. 6, Rec7HA3 co-precipitated only when Rec24TAP4 was present in the protein extracts. This result confirms the interaction of Rec7 and Rec24. The occurrence of this interaction in both experimental systems, the $\mathrm{Y} 2 \mathrm{H}$ analysis and the co-immunoprecipitation experiment, suggests that the mutual interaction is not dependent on fission yeast post-translational modifications.

Loss of interaction between Rec7 and Rec24 leads to recombination deficiency

To test whether the lost interaction of Rec7F325A with $\mathrm{Rec} 24$ in the $\mathrm{Y} 2 \mathrm{H}$ analysis is relevant for a functional $S$. pombe meiotic recombination initiation complex and thus for wild-type recombination levels, we integrated rec7F325A as well as $\mathrm{rec} 7$ wild-type sequences into the lys 1 locus in a rec $7 \Delta$ strain and checked for complementation of recombination deficiency by measuring intragenic recombination between ade6-M26 and ade6-469. Both constructs were under the control of a thiamine-repressible promotor. Heterozygous lys $1:: \operatorname{rec} 7 \mathrm{x}$ rec $7 \Delta$ crosses showed similar recombination proficiency under derepressing conditions (no thiamine) than heterozygous $\operatorname{rec} 7 \mathrm{x}$ rec $7 \Delta$ crosses (Fig. 7a). The addition of thiamine to the sporulation media decreases the recombination level (Fig. 7b) indicating a need for high amounts of Rec7 protein. Heterozygous crosses lys $1: \because \operatorname{rec} 7 \mathrm{~F} 325 \mathrm{~A} \times \operatorname{rec} 7 \Delta$, however, were indistinguishable from homozygous $\mathrm{rec} 7 \Delta$ $\mathrm{x} \operatorname{rec} 7 \Delta$ crosses. Spore viability of these crosses was not significantly different from the spore viability of the homozygous $\operatorname{rec} 7 \Delta$ cross (Table S4). Western blot analysis confirmed that a myc epitope tagged Rec7F325A was expressed (Figure S1).

In conclusion we can say, that the consequence of interaction loss between Rec7F325A and Rec24 in the Y2H analysis converts into a meiotic recombination deficiency of 


\begin{tabular}{l|l} 
Scer & YMR133W \\
Spar & spar166-g1.1 \\
Smik & smik297-g1.1 \\
Sbay & sbayc657-g38.1 \\
Sklu & SAKLOE04774g \\
Agos & ADR244W \\
Soct & SOCG02901 \\
Spom & SPCC1753.03c \\
Klac & KLLA0F17195g \\
Kwal & Kwal47.17837 \\
Scas & Scas684.8d \\
Cgla & CAGL0K03905g
\end{tabular}
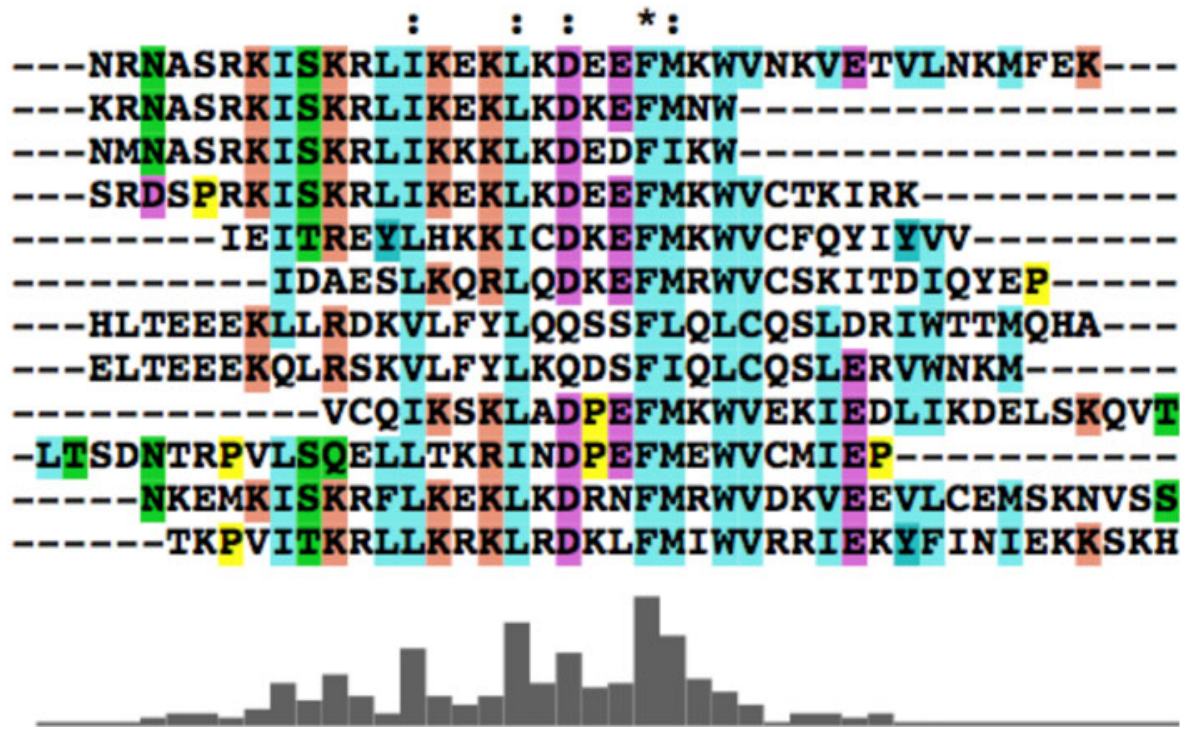

Fig. 5 Multiple sequence alignment of the $\mathrm{C}$ terminus of Rec7 homologs. Sequences homologs from various ascomycetes of Rec7 were aligned with the CLUSTAL-X program. The very C-terminal patch of homology is shown, containing the $\mathrm{C}$ terminal ends of all homologs. Positions with similar amino acids are indicated with vertical double dots above the aligned sequences, whereas identical amino acids are indicated with a star. The bar diagram below the aligned sequences indicates the amount of homology in an arbitrary scale

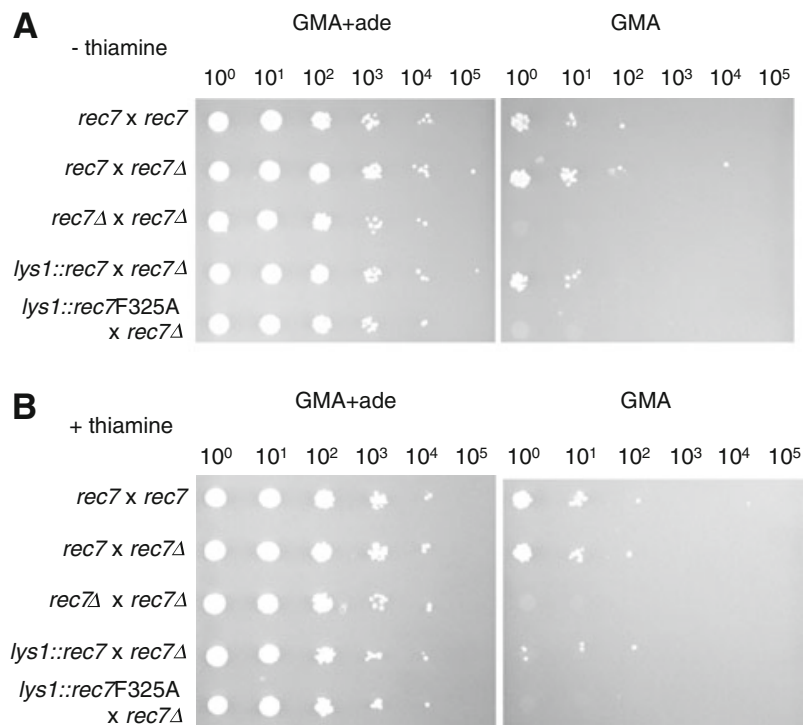

Fig. 7 Recombination is abolished in rec7F325A. Undiluted and tenfold dilutions of spore suspensions from derepressed (a, SPO media) or repressed conditions (b, SPO media with thiamine) of homozygous rec 7 , heterozygous rec $7 \Delta$, homozygous rec $7 \Delta$, heterozygous lys $1:: P_{n m t 1}-r e c 7$, and heterozygous lys $1:: P_{n m t 1}-$ rec $7 F 325 A$ crosses, grown on minimal media containing adenine (GMA+ade, left panel) or on minimal media without adenine (GMA, right panel)

following tentative sub-complexes: Rec7/Rec24/Rec15/ Mde2 and Rec12/Rec14/Rec6. The decreased, but not erased recombination level of Rec12Q308A and Rec12 R309A might suggest that another contact point between Rec12 and Rec14 exists, maybe through Rec6. 
Assembly of the meiotic recombination initiation complex must happen in several, distinguishable steps. First, meiotic cohesins Rec8 and Rec11 load on chromosomes. Next, proteins of the LinEs (Rec10, Rec25, and Rec27) accumulate in a cohesin-dependent manner. As suggested by Lorenz et al. (2006), the LinEs might then serve as a loading platform for proteins or sub-complexes that are more directly involved in the actual DSB formation process. Their results indicate that Rec7, and probably the other members of its sub-complex Rec24, Rec15, and Mde2, locate in a Rec10-dependent way on chromatin. Our results with the thiamine-repressible promotor also suggest that the amount of Rec7 is crucial for the initiation process. Rec7 loading is not dependent on Rec12, which must mean that Rec12 and its probable sub-complex is loaded afterwards.

It remains to be investigated which factors influence the interplay between these sub-complexes. Further experiments are needed to elucidate the true composition and functional relevance of the proposed sub-complexes in the time frame of meiosis.

Acknowledgments We thank Marc-David Ruepp and Kathleen Gould for plasmids, Valerie Borde, Cristina Martin-Castellanos, Jurai Gregan, and Franz Klein for helpful discussions. Our acknowledgements for $S$. cerevisiae strains and $\mathrm{Y} 2 \mathrm{H}$ plasmids go to T. N. Davis, grant P41 RR11823 from the National Center for Research Resources at the National Institutes of Health. The study was supported by the Swiss National Science Foundation to JK and KL. KL was supported by the UniBern Forschungstiftung and SS by a short-term fellowship of the Boehringer Ingelheim Fonds.

\section{References}

Arora C, Kee K, Maleki S, Keeney S (2004) Antiviral protein Ski8 is a direct partner of Spo11 in meiotic DNA break formation, independent of its cytoplasmic role in RNA metabolism. Mol Cell 13(4):549-559

Ausubel F, Brent R, Kingston R, Moore D, Seidman J, Smith J, Struhl K (2009) Current Protocols in Molecular Biology. 5 vols, vol 4. John Wiley \& Sons, Inc

Bähler J, Wyler T, Loidl J, Kohli J (1993) Unusual nuclear structures in meiotic prophase of fission yeast: a cytological analysis. J Cell Biol 121(2):241-256

Bähler J, Wu JQ, Longtine MS, Shah NG, McKenzie A, Steever AB, Wach A, Philippsen P, Pringle JR (1998) Heterologous modules for efficient and versatile PCR-based gene targeting in Schizosaccharomyces pombe. Yeast 14(10):943-951

Basi G, Schmid E, Maundrell K (1993) Tata box mutations in the Schizosaccharomyces pombe nmt1 promoter affect transcription efficiency but not the transcription start point or thiamine repressibility. Gene 123(1):131-136

Beach D (1985) Sexual differentiation is controlled by a protein kinase encoded by the ran1+ gene in fission yeast. Cold Spring Harb Symp Quant Biol 50:635-641

Bergerat A, de Massy B, Gadelle D, Varoutas PC, Nicolas A, Forterre P (1997) An atypical topoisomerase II from archaea with implications for meiotic recombination. Nature 386(6623):414-417
Bishop DK, Nikolski Y, Oshiro J, Chon J, Shinohara M, Chen X (1999) High copy number suppression of the meiotic arrest caused by a dmc1 mutation: Rec114 imposes an early recombination block and rad54 promotes a dmc1-independent DSB repair pathway. Genes Cells 4(8):425-444

Borde V (2007) The multiple roles of the Mre11 complex for meiotic recombination. Chromosome Res 15(5):551-563

Carballo JA, Johnson AL, Sedgwick SG, Cha RS (2008) Phosphorylation of the axial element protein Hop1 by Mec1/Tel1 ensures meiotic interhomolog recombination. Cell 132(5):758-770

Caspari T, Dahlen M, Kanter-Smoler G, Lindsay HD, Hofmann K, Papadimitriou K, Sunnerhagen P, Carr AM (2000) Characterization of Schizosaccharomyces pombe Hus1: a pcna-related protein that associates with Rad1 and Rad9. Mol Cell Biol 20(4):1254-1262

Cervantes MD, Farah JA, Smith GR (2000) Meiotic DNA breaks associated with recombination in s. pombe. Mol Cell 5(5):883888

Cheng Z, Liu Y, Wang C, Parker R, Song H (2004) Crystal structure of Ski8p, a WD-repeat protein with dual roles in mRNA metabolism and meiotic recombination. Protein Sci 13(10): 2673-2684

Chikashige Y, Kurokawa R, Haraguchi T, Hiraoka Y (2004) Meiosis induced by inactivation of Pat 1 kinase proceeds with aberrant nuclear positioning of centromeres in the fission yeast Schizosaccharomyces pombe. Genes Cells 9(8):671-684

Chikashige Y, Tsutsumi C, Yamane M, Okamasa K, Haraguchi T, Hiraoka Y (2006) Meiotic proteins Bqt1 and Bqt2 tether telomeres to form the bouquet arrangement of chromosomes. Cell 125(1):59-69

Davis L, Smith GR (2003) Nonrandom homolog segregation at meiosis I in Schizosaccharomyces pombe mutants lacking recombination. Genetics 163(3):857-874

Davis L, Rozalen AE, Moreno S, Smith GR, Martin-Castellanos C (2008) Rec25 and Rec27, novel linear-element components, link cohesin to meiotic DNA breakage and recombination. Curr Biol 18(11):849-854

De Veaux LC, Hoagland NA, Smith GR (1992) Seventeen complementation groups of mutations decreasing meiotic recombination in Schizosaccharomyces pombe. Genetics 130(2):251-262

Deutschbauer AM, Jaramillo DF, Proctor M, Kumm J, Hillenmeyer ME, Davis RW, Nislow C, Giaever G (2005) Mechanisms of haploinsufficiency revealed by genome-wide profiling in yeast. Genetics 169(4):1915-1925

Doll E, Molnar M, Hiraoka Y, Kohli J (2005) Characterization of Rec15, an early meiotic recombination gene in Schizosaccharomyces pombe. Curr Genet 48(5):323-333

Evans DH, Li YF, Fox ME, Smith GR (1997) A WD repeat protein, Rec14, essential for meiotic recombination in Schizosaccharomyces pombe. Genetics 146(4):1253-1264

Fox ME, Smith GR (1998) Control of meiotic recombination in Schizosaccharomyces pombe. Prog Nucleic Acid Res Mol Biol 61:345-378

Gregan J, Rabitsch PK, Sakem B, Csutak O, Latypov V, Lehmann E, Kohli J, Nasmyth K (2005) Novel genes required for meiotic chromosome segregation are identified by a highthroughput knockout screen in fission yeast. Curr Biol 15(18): 1663-1669

Gutz H, Heslot H, Leupold U, Loprieno N (1974) Schizosaccharomyces pombe. Handb Genet 1:395-446

Henderson KA, Kee K, Maleki S, Santini PA, Keeney S (2006) Cyclin-dependent kinase directly regulates initiation of meiotic recombination. Cell 125(7):1321-1332

Hudson JRJ, Dawson EP, Rushing KL, Jackson CH, Lockshon D, Conover D, Lanciault C, Harris JR, Simmons SJ, Rothstein R, Fields S (1997) The complete set of predicted genes from 
Saccharomyces cerevisiae in a readily usable form. Genome Res 7(12):1169-1173

James P, Halladay J, Craig EA (1996) Genomic libraries and a host strain designed for highly efficient two-hybrid selection in yeast. Genetics 144(4):1425-1436

Jiao K, Salem L, Malone R (2003) Support for a meiotic recombination initiation complex: interactions among Rec102p, Rec104p, and Spo11p. Mol Cell Biol 23(16):5928-5938

Kee K, Keeney S (2002) Functional interactions between Spo11 and Rec102 during initiation of meiotic recombination in Saccharomyces cerevisiae. Genetics 160(1):111-122

Kee K, Protacio RU, Arora C, Keeney S (2004) Spatial organization and dynamics of the association of Rec102 and Rec104 with meiotic chromosomes. Embo J 23(8):1815-1824

Keeney S (2001) Mechanism and control of meiotic recombination initiation. Curr Top Dev Biol 52:1-53

Keeney S, Giroux CN, Kleckner N (1997) Meiosis-specific DNA double-strand breaks are catalyzed by Spo11, a member of a widely conserved protein family. Cell 88(3):375-384

Kitajima TS, Yokobayashi S, Yamamoto M, Watanabe Y (2003) Distinct cohesin complexes organize meiotic chromosome domains. Science 300(5622):1152-1155

Latypov V, Rothenberg M, Lorenz A, Octobre G, Csutak O, Lehmann E, Loidl J, Kohli J (2010) The roles of Hop1 and Mek1 in meiotic chromosome pairing and recombination-partner choice in Schizosaccharomyces pombe. Mol Cell Biol. doi:10.1128/ MCB.00919-09

Li J, Hooker GW, Roeder GS (2006) Saccharomyces cerevisiae Mer2, Mei4 and Rec114 form a complex required for meiotic doublestrand break formation. Genetics 173(4):1969-1981

Lichten M (2008) Meiotic chromatin: the substrate for recombination initiation. In: Egel R, Lankenau D-H (eds) Recombination and meiosis-models, means, and evolution vol 3. Springer, Berlin, Heidelberg, pp 165-193

Lorenz A, Wells JL, Pryce DW, Novatchkova M, Eisenhaber F, McFarlane RJ, Loidl J (2004) S pombe meiotic linear elements contain proteins related to synaptonemal complex components. J Cell Sci 117(Pt 15):3343-3351

Lorenz A, Estreicher A, Kohli J, Loidl J (2006) Meiotic recombination proteins localize to linear elements in Schizosaccharomyces pombe. Chromosoma 115(4):330-340. doi:10.1007/s00412-0060053-9

Ludin K, Jiang R, Carlson M (1998) Glucose-regulated interaction of a regulatory subunit of protein phosphatase 1 with the Snf1 protein kinase in Saccharomyces cerevisiae. Proc Natl Acad Sci U S A 95(11):6245-6250

Ludin K, Mata J, Watt S, Lehmann E, Bahler J, Kohli J (2008) Sites of strong Rec12/Spo11 binding in the fission yeast genome are associated with meiotic recombination and with centromeres. Chromosoma 117(5):431-444

Madrona AY, Wilson DK (2004) The structure of Ski8p, a protein regulating mRNA degradation: Implications for WD protein structure. Protein Sci 13(6):1557-1565

Maleki S, Neale MJ, Arora C, Henderson KA, Keeney S (2007) Interactions between Mei4, Rec114, and other proteins required for meiotic DNA double-strand break formation in Saccharomyces cerevisiae. Chromosoma 116(5):471-486

Mao-Draayer Y, Galbraith AM, Pittman DL, Cool M, Malone RE (1996) Analysis of meiotic recombination pathways in the yeast Saccharomyces cerevisiae. Genetics 144(1):71-86

Martin-Castellanos C, Blanco M, Rozalen AE, Perez-Hidalgo L, Garcia AI, Conde F, Mata J, Ellermeier C, Davis L, San-Segundo $\mathrm{P}$, Smith GR, Moreno S (2005) A large-scale screen in $S$ pombe identifies seven novel genes required for critical meiotic events. Curr Biol 15(22):2056-2062
Matsumoto Y, Sarkar G, Sommer SS, Wickner RB (1993) A yeast antiviral protein, Ski8, shares a repeated amino acid sequence pattern with beta-subunits of $\mathrm{g}$ proteins and several other proteins. Yeast 9(1):43-51

Molnar M, Bähler J, Sipiczki M, Kohli J (1995) The rec8 gene of Schizosaccharomyces pombe is involved in linear element formation, chromosome pairing and sister-chromatid cohesion during meiosis. Genetics 141(1):61-73

Molnar M, Bähler J, Kohli J, Hiraoka Y (2001a) Live observation of fission yeast meiosis in recombination-deficient mutants: a study on achiasmate chromosome segregation. J Cell Sci $114(\mathrm{Pt}$ 15):2843-2853

Molnar M, Parisi S, Kakihara Y, Nojima H, Yamamoto A, Hiraoka Y, Bozsik A, Sipiczki M, Kohli J (2001b) Characterization of Rec7, an early meiotic recombination gene in Schizosaccharomyces pombe. Genetics 157(2):519-532

Moreno S, Klar A, Nurse P (1991) Molecular genetic analysis of fission yeast Schizosaccharomyces pombe. Methods Enzymol 194:795-823

Neale MJ, Pan J, Keeney S (2005) Endonucleolytic processing of covalent protein-linked DNA double-strand breaks. Nature 436(7053): 1053-1057

Nurse P, Thuriaux P, Nasmyth K (1976) Genetic control of the cell division cycle in the fission yeast Schizosaccharomyces pombe. Mol Gen Genet 146(2):167-178

Parisi S, McKay MJ, Molnar M, Thompson MA, van der Spek PJ, van Drunen-Schoenmaker E, Kanaar R, Lehmann E, Hoeijmakers JH, Kohli J (1999) Rec8p, a meiotic recombination and sister chromatid cohesion phosphoprotein of the $\operatorname{Rad} 21 \mathrm{p}$ family conserved from fission yeast to humans. Mol Cell Biol 19(5):3515-3528

Ponticelli AS, Smith GR (1989) Meiotic recombination-deficient mutants of Schizosaccharomyces pombe. Genetics 123(1):45-54

Prieler S, Penkner A, Borde V, Klein F (2005) The control of Spo11's interaction with meiotic recombination hotspots. Genes Dev 19(2):255-269

Puizina J, Siroky J, Mokros P, Schweizer D, Riha K (2004) Mre11 deficiency in Arabidopsis is associated with chromosomal instability in somatic cells and Spo11-dependent genome fragmentation during meiosis. Plant Cell 16(8):1968-1978

Ridley SP, Sommer SS, Wickner RB (1984) Superkiller mutations in Saccharomyces cerevisiae suppress exclusion of $\mathrm{m} 2$ doublestranded RNA by 1-a-hn and confer cold sensitivity in the presence of $\mathrm{m}$ and 1-a-hn. Mol Cell Biol 4(4):761-770

Rothenberg M, Kohli J, Ludin K (2009) Ctp1 and the MRN-complex are required for endonucleolytic Rec12 removal with release of a single class of oligonucleotides in fission yeast. PLoS Genet 5(11):e1000,722

Salem L, Walter N, Malone R (1999) Suppressor analysis of the Saccharomyces cerevisiae gene rec104 reveals a genetic interaction with rec102. Genetics 151(4):1261-1272

Sasanuma H, Murakami H, Fukuda T, Shibata T, Nicolas A, Ohta K (2007) Meiotic association between Spo11 regulated by Rec102, Rec104 and Rec114. Nucleic Acids Res 35(4):1119-1133

Sasanuma H, Hirota K, Fukuda T, Kakusho N, Kugou K, Kawasaki Y, Shibata T, Masai H, Ohta K (2008) Cdc7-dependent phosphorylation of Mer2 facilitates initiation of yeast meiotic recombination. Genes Dev 22(3):398-410

Smith TF, Gaitatzes C, Saxena K, Neer EJ (1999) The WD repeat: a common architecture for diverse functions. Trends Biochem Sci 24(5):181-185

Thompson JD, Higgins DG, Gibson TJ (1994) Clustal W: improving the sensitivity of progressive multiple sequence alignment through sequence weighting, position-specific gap penalties and weight matrix choice. Nucleic Acids Res 22(22):4673-4680 
Uetz P, Giot L, Cagney G, Mansfield TA, Judson RS, Knight JR, Lockshon D, Narayan V, Srinivasan M, Pochart P, QureshiEmili A, Li Y, Godwin B, Conover D, Kalbfleisch T, Vijayadamodar G, Yang M, Johnston M, Fields S, Rothberg JM (2000) A comprehensive analysis of protein-protein interactions in Saccharomyces cerevisiae. Nature 403(6770):623-627

Wan L, Niu H, Futcher B, Zhang C, Shokat KM, Boulton SJ, Hollingsworth NM (2008) Cdc28-Clb5 (CDK-S) and Cdc7-Dbf4 (DDK) collaborate to initiate meiotic recombination in yeast. Genes Dev 22(3):386-397

Xu L, Weiner BM, Kleckner N (1997) Meiotic cells monitor the status of the interhomolog recombination complex. Genes Dev 11(1):106-118
Yamamoto A, Hiraoka Y (2003) Monopolar spindle attachment of sister chromatids is ensured by two distinct mechanisms at the first meiotic division in fission yeast. Embo J 22(9):2284-2296

Young JA, Schreckhise RW, Steiner WW, Smith GR (2002) Meiotic recombination remote from prominent DNA break sites in $S$ pombe. Mol Cell 9(2):253-263

Young JA, Hyppa RW, Smith GR (2004) Conserved and nonconserved proteins for meiotic DNA breakage and repair in yeasts. Genetics 167(2):593-605

Zickler D, Kleckner N (1999) Meiotic chromosomes: integrating structure and function. Annu Rev Genet 33:603-754 